\title{
Revista Brasileira de Enfermagem REBEn \\ Representações Sociais das implicações legais da infecção hospitalar e de seu controle
}

\author{
Social Representations of the legal implications of nosocomial infection and its control \\ Representaciones Sociales de las implicaciones legales de la infección hospitalária y \\ sú control
}

\section{Cristina Maria Miranda de Sousa}

Pesquisadora, Advogada. Doutoranda do Programa de Pós-Graduação em Ciências da Saúde da Universidade Federal do Rio Grande do Norte - UFRN, Natal, RN. Líder do Grupo de Estudos e Pesquisa sobre Representações Sociais da Faculdade NOVAFAPI

Endereço para Contato Rua Desembargador Manoel Castelo Branco, 1605 - Edifício Pegasus - Apt 600 - Jockey Club. CEP: 640492 70. Teresina, PI. cristinamiranda@novafapi.com.br

Maria do Socorro Feitosa

Doutora em Odontologia Preventiva e Social. Professora do Programa de PósGraduação em Ciências da Saúde, NOVAFAPI, Teresina, $P I$ alfa@ufrnet.br

\section{Maria Eliete Batista Moura}

Doutora em Enfermagem. Coordenadora de Pesquisa e Pós-Graduação da Faculdade NOVAFAPI, Teresina, PI. Docente da Graduação e do Mestrado em Enfermagem da Universidade Federal do Piauí (UFPI). posgraduacao@novafapi.com.br

Antonia Oliveira Silva

Doutora em Enfermagem. Docente do Programa de Pós-Graduação em Enfermagem da UFPB, João Pessoa, $P B$. alfaleda@yahoo.com.br

\footnotetext{
Submissão: 10/05/2007
}

Aprovação: 10/07/2007

\section{RESUMO}

O estudo objetivou apreender as Representações Sociais das implicações legais da infecção hospitalar (IH) e analisar como essas representações se articulam com a qualidade do trabalho desenvolvido pelos profissionais da saúde e de direito. Os dados foram produzidos através de entrevistas e processados pelo software Alceste 4.8. A análise hierárquica descendente mostrou 04 classes de palavras, que objetivaram as implicações legais da $\mathrm{IH}$, ancoradas nos aspectos ideológicos, históricos e sócio-culturais, no direito que o usuário da saúde tem de não correr riscos, resultantes de ocorrências causadas por negligência dos envolvidos no processo, devendo ser fiscalizadas pelos órgãos competentes para que os responsáveis respondam civilmente e penalmente, pelo descaso ou descuido na assistência hospitalar.

Descritores: Direito à saúde; Psicologia Social; Infecção hospitalar.

\section{ABSTRACT}

The study aimed at learning the social representations of the legal implications of hospital infections (HI) and analyze how these representations are articulated with the quality of work developed by the health and law professionals. The data were produced through interviews and processed by software Alceste4.8. The descendant hierarchical analysis showed 04 classes of words, that objected the legal implications of $\mathrm{HI}$, anchored in the ideological, historical and socio-cultural aspects, in the rights that the health user has not run risks, resulting of occurences caused by negligence of involved in the process having to be fiscalized by the competent organs in order the responsibles answer civily and penaltily, miscase or miscare in hospital assistance.

Descriptors: Rights to health; Psychology, Social; Hospital infection.

\section{RESUMEN}

El estudio objectivó aprehender las representaciones sociales de las implicaciones legales de la infección hospitalaria $(\mathrm{IH})$ y analizar como esas representaciones se articulan con la cualidad de trabajo desarrollado por los profesionales de la salud y de derecho. Los datos fueron producidos a través de encuestas y procesados por el software Alceste 4.8. El analisis jierarquico decendiente enseñó 04 clases de palabras que objectivaron las impliciones legales de IH , atracado en los aspectos ideológicos, históricos y socioculturales, en el derecho que el usuario de la salud tiene de no correr riesgos, resultantes de ocurrencias causadas por negligencia de los involuncrados en el proceso, debendo ser fiscalizado por los órganos competentes para que los responsables contesten civilmente y penalmente, por el descaso y descuido en asistencia hospitalaria.

Descriptores: Derecho a la salud; Psicología Social; Infección hospitalaria.

Sousa CMAM, Feitosa MS, Moura MEB, Silva AO. Representações Sociais das implicações legais da infecção hospitalar e seu controle. Rev Bras Enferm 2007 jul-ago; 60(4):428-33.

\section{INTRODUÇÃO}

A infecção hospitalar $(\mathrm{IH})$ representa atualmente uma preocupação, não somente dos órgãos de saúde competentes, mas como um problema de ordem social, ética e jurídica em face às implicações na vida dos usuários e o risco que estes estão submetidos.

Dessa forma, a IH tanto no Brasil como no mundo, significa importante problema de saúde pública ${ }^{(1)}$. $\mathrm{O}$ aparecimento dos microorganismos multirresistentes aos antibióticos, os avanços tecnológicos relacionados aos procedimentos invasivos, diagnósticos e terapêuticos, constituem riscos à saúde dos usuários. Mesmo com a legislação vigente no país, os dados sobre $\mathrm{IH}$ são pouco divulgados pelo fato de não serem consolidados por muitos hospitais, o que tem dificultado a aquisição de um diagnóstico que retrate a dimensão do problema no país(2). 
Uma pesquisa realizada e publicada em 1995 no Brasil, mostrou que o problema da infecção hospitalar é considerado grave uma vez que o índice nos hospitais brasileiros é de $15,5^{(3)}$.

Essa problemática no Estado do Piaui é caracterizada por uma taxa de prevalência de $\mathrm{IH}$ nos hospitais de referência, localizados na capital Teresina, expressa, inicialmente no Hospital Areolino de Abreu, 37,7\%; a seguirem: Maternidade Dona Evangelina Rosa, 11,3\%; Hospital Infantil Lucídio Portela, 35,7\%; Instituto de Doenças Tropicais Natan Portela, 23,7\%, e o Hospital Getúlio Vargas, que funciona há 59 anos, possui quatrocentos e vinte e nove leitos, tem Comissões de Controle de Infecção Hospitalar $(\mathrm{CClH})$ e Serviço de Controle de Infecção Hospitalar (SCIH) estruturado, possui uma taxa de prevalência de $\mathrm{IH}$ de $31,1 \%$ (4).

Além disso, as implicações advindas das infecções hospitalares recaem sobre os profissionais e as instituições prestadoras de serviços de saúde e traz repercussões penais, civis e éticas, as quais nascem em decorrência de atos falhos cometidos pelos profissionais e acabam gerando conseqüências danosas aos seus clientes.

Muitos profissionais da área de saúde não se preocupam com os deveres éticos e jurídicos que Ihes possam responsabilizar pelo exercício de sua profissão. Atualmente, são inúmeros os casos de omissões, além de outras desagradáveis conseqüências de imperícia, negligência, ou imprudência, pela representação político-social das infecções hospitalares e de seu controle.

Salientar tais implicações configura uma forma de refletir sobre as conseqüências para os profissionais da área de saúde obrigando-os a responderem pelos seus atos, quando culpado o agente ou a instituição, nos diferentes níveis: legal, subdividida em civil e penal, e a ética ou moral. Tal situação deixa evidenciar contradições entre o direito à saúde, por um lado, e, por outro, a limitação dos meios da realização coletiva desse direito.

\subsection{Representações Sociais no Contexto das IH}

Nos últimos anos, a teoria das representações sociais tem adquirido força no campo das investigações na área da saúde, por comportar diferentes abordagens de estudos e métodos. Logo, tem suscitado um amplo espaço de discussão e pesquisa, capaz de possibilitar um melhor entendimento sobre atividades cognitivas, simbólicas e afetivas dos indivíduos nas suas interações cotidianas e tomadas de posicionamentos sociais.

Um grande número de pesquisadores tem-se interessado por esse aporte teórico pela possibilidade de estudar a produção simbólica como uma forma de realizar pesquisas mais criativas, pela valorização do saber popular, pela possibilidade de revelar situações do cotidiano da prática não visíveis objetivamente e pelo estudo da sensibilidade e da emoção(5).

No Brasil, a saúde constitui um direito do povo e dever do Estado, retratada no artigo 6 da Constituição Federal de 1988(6); mas como garantir o direito à saúde do povo brasileiro, se o conceito de saúde encontra-se imbricado a direitos mais amplos? Envolve direito à alimentação, à moradia, a proteção contra as situações que causam stress, a segurança no trabalho, o laser e também o direito de ser atendido nos serviços de saúde sem riscos de complicações por iatrogenia da equipe de saúde, como a aquisição de uma infecção hospitalar.

Os estudos, na área da saúde e de direito, pela perspectiva da Teoria das Representações Sociais (TRS) possibilita à aquisição de um conhecimento socialmente compartilhado e vinculado às construções sociais a partir de um saber específico do senso comum, influenciado pelos comportamentos e atitudes dos grupos sociais, particularmente, face aos direitos do homem à ética e a moral, envolvendo as infecções hospitalares.

As representações sociais enfatizam a construção social, ou melhor, a forma como a pessoa pensa o seu universo; resultam em um conhecimento socialmente construído por meio de discurso nos grupos ${ }^{(7)}$.

O conceito de Representação Social foi originado na Europa com a publicação feita por Serge Moscovici, do seu estudo sobre a representação social da psicanálise, como: "Um sistema de valores, de noções e de práticas tendo uma dupla tendência: antes de tudo, instaurar uma ordem que permite aos indivíduos a possibilidade de se orientar no meio ambiente social, material e de dominá-lo. Em seguida, de assegurar a comunicação entre os membros de uma comunidade, propondo-Ihes um código para suas trocas e um código para nomear e classificar de maneira unívoca as partes de seu mundo, de sua história individual ou coletiva"(8).

Partindo dessas considerações este estudo tem como objetivos, apreender as Representações Sociais sobre as Implicações Legais da Infecção Hospitalar e de seu Controle e analisar como essas representações se articulam com a qualidade do trabalho desenvolvido pelos profissionais da saúde e de direito relacionadas com a prevenção e controle das infecções hospitalares.

A partir do conhecimento das representações sociais é possivel se propor estratégias de intervenção direcionadas aos serviços e profissionais capazes de refletirem sobre a problemática da infecção hospitalar e adoção de medidas contextualizadas com a realidade estudada.

\section{METODOLOGIA}

Trata-se de uma pesquisa exploratória, para analisar fenômenos sócioculturais a partir das representações sociais acerca das implicações legais da infecção hospitalar e de seu controle, subsidiadas na teoria das representações sociais. 0 cenário da pesquisa foi um hospital público e de referência, localizado em Teresina - PI. Os sujeitos da pesquisa foram 16 profissionais de saúde, médicos, enfermeiros, dentistas e advogados do referido hospital.

No trabalho de campo foi utilizada a técnica de entrevista em profundidade, como instrumento de pesquisa, por ser considerada importante no trabalho de campo na pesquisa qualitativa, facilitando a compreensão da realidade social(9).

Após a aceitação verbal dos sujeitos do estudo, foi solicitado aos mesmos que assinassem o termo de consentimento livre e esclarecido, que obedece aos preceitos éticos e legais conforme o Comitê de Ética e Pesquisa - CEP/NOVAFAPI, acordado com os requisitos da Resolução 196/96, que trata das diretrizes e normas de pesquisa envolvendo seres humanos ${ }^{(10)}$

Os dados produzidos foram processados pelo software Alceste 4.8 criado por Reinert, na França, no final dos anos $70^{(11)}$, introduzido no Brasil em 1998, que permite efetuar de maneira automática a análise de entrevistas, e tem como objetivo quantificar um texto para extrair o mais forte significado de uma estrutura.

O tratamento e análise dos dados permitiram as deduções sobre a organização do sistema de pensamento dos sujeitos produtores dos discursos, apontando as representações sociais das implicações legais da IH.

\section{RESULTADOS E DISCUSSÃO}

\section{Conteúdos e Dimensões das Representações Sociais das} Implicações Legais da IH e seu Controle

Nos dados obtidos do conjunto de entrevistas (corpus) analisados, observa-se quatro classes semânticas (categorias) e a associação das mesmas com as variáveis do estudo, gênero, idade e profissão, as quais representaram $100 \%$ do material submetido à análise.

O corpus analisado no estudo é composto de dezesseis unidades de contexto inicial ( $\mathrm{UCl}$ ) ou entrevistas e foi dividido em 280 unidades de contexto elementar (UCE).

Do material analisado obteve-se a análise hierárquica descendente representada na seguinte distribuição de classes ou contextos temáticos, com conteúdos diferenciados nas representações sociais contempladas a seguir.

O dendograma da Figura 1 representa $75 \%$ das UCEs (unidades de contexto elementar) recortadas do texto (das 373 UCEs identificadas foram classificadas 280) e distribuídas nas classes (categorias) com os 


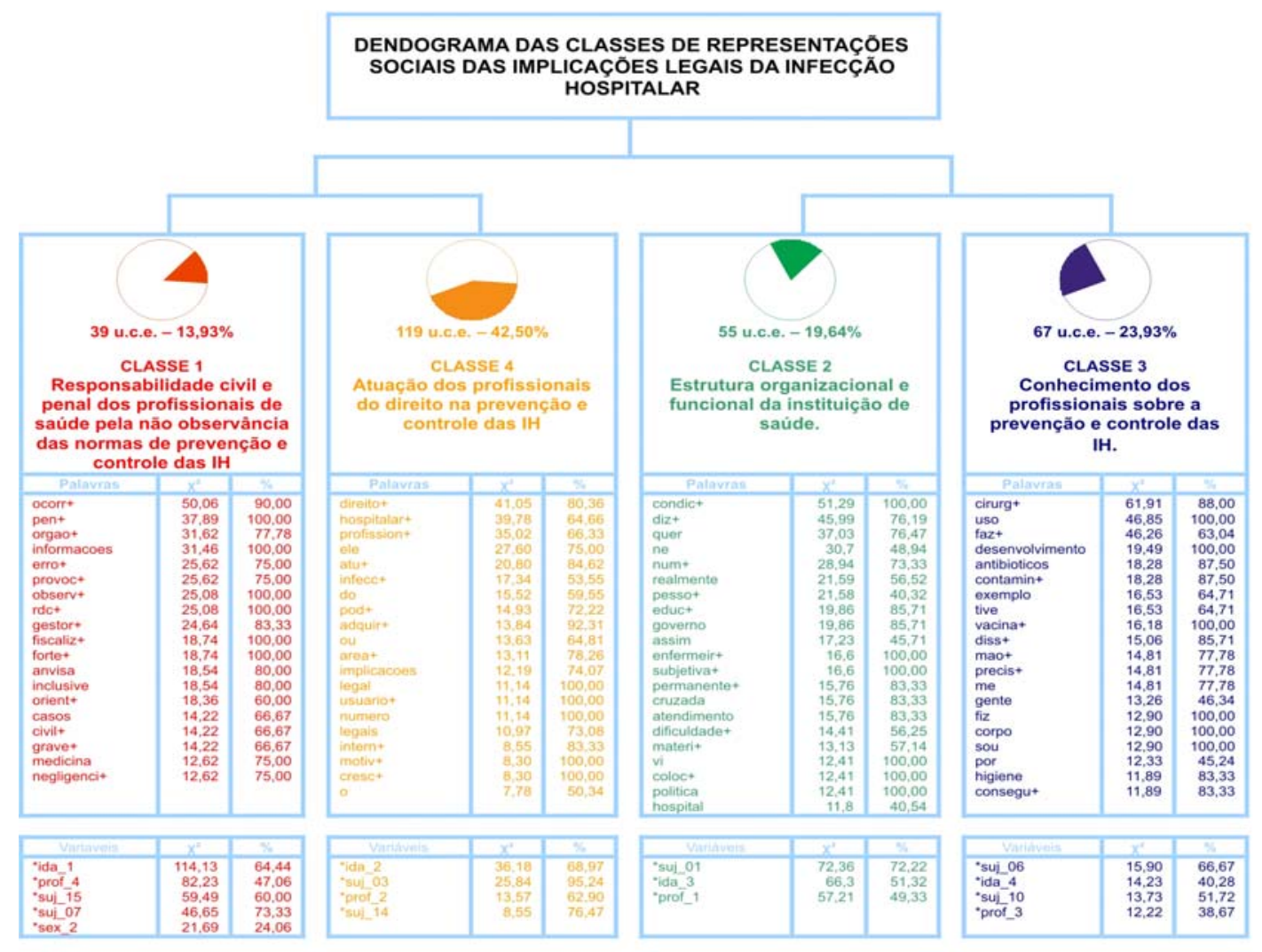

Figura 1. Estrutura temática das Representações Sociais das implicações legais da infecção hospitalar.

conteúdos a serem interpretados a seguir.

Classe 1 - Descrições sobre as implicações civil e penal dos profissionais de saúde pela não observância das normas de prevenção e controle das IH

A classe número um, associada diretamente à classe quatro, constituída pelas 39 UCEs, concentra $13,93 \%$ das UCEs classificadas, extraídas predominantemente das entrevistas 7 e 15 , dos profissionais advogados na faixa etária de 20 a 30 anos do sexo masculino. Observa-se que é 0 texto temático menos contributivo. Assim, os vocábulos em suas formas reduzidas, selecionadas pela freqüência e pelos valores de $\div$ mais elevados na classe, são responsáveis pelas representações sociais dos profissionais de saúde sobre as implicações legais da IH de acordo com o gráfico 1.

Os conteúdos apreendidos denotam uma preocupação dos profissionais quanto à necessidade de se respeitar o direito que o usuário da saúde tem em não correr riscos resultantes de ocorrências que devem ser fiscalizadas pela a Agência Nacional de Vigilância Sanitária (ANVISA) e pelos gestores das instituições de saúde, conforme atesta os exemplos seguintes:

As implicações legais da infecção hospitalar, quando causada por erro, seja negligência ou dolo, ela vem a ser implicada numa responsabilidade médica em decorrência dos danos que deverão ser ressarcidos (...) Em minha opinião eles poderão responder civilmente e penalmente, pelo descaso ou descuido com adoção de ações de responsabilidade civil e penal(...) Essas pessoas devem responder realmente não só perante seus conselhos, não só também perante um órgão como também pelo judiciário através de indenizações, através de penas privativas de liberdade ou penas privativas de direito(...) A equipe que estava acompanhando o paciente pode ser responsabilizada tanto civil como penal e pode levar inclusive o paciente a óbito e a repercussão mais grave ainda(...)

No atual momento da nossa história, tem-se que a saúde é um dos direitos humanos mais importantes, e que sua defesa e promoção exigem 0 envolvimento do Estado. Para tanto, a Constituição Federal de 1988(6) definiu saúde como direito de todos e dever do Estado a ser garantido mediante políticas sócias e econômicas que visem à redução do risco de doenças e de outros agravos e 0 acesso universal e igualitário às ações e serviços.

Quanto ao programa normativo fixado pelo Texto Constitucional o mesmo deve ser concretizado através de prestações legislativas e administrativas a cargo do Estado, de tal forma a dar eficácia a este direito. Trata-se, pois, de imposições constitucionais consubstanciadas em fins e tarefas dirigidas ao Estado e à sociedade, os quais, de forma democrática, deverão conferir uma estruturação prática a este direito nas três esferas de governo (Federal, Estadual e Municipal).

A partir das representações apreendidas é possível perceber que a impunidade aos profissionais de saúde os acomoda a recorrerem a práticas preventivas nos serviços. Os profissionais apontam que os piores índices de saúde encontram-se entre os grupos populacionais mais vulneráveis localizados na base da pirâmide social, observadas a partir das condições de vida e saúde dos usuários. Partindo desse princípio, é fundamental não só aos profissionais de saúde, como também ao Estado, procurar minimizar as diferenças que advém de fatores consideráveis evitáveis e injustos, dando oportunidade de igualdade a todos ${ }^{(12)}$.

No tocante à responsabilidade das instituições e gestores dos serviços de saúde, neste estudo, as UCEs são indicativas de que seja adotada uma política de controle de $\mathrm{IH}$, com base na Portaria $2616^{(13)}$, na Resolução da Diretoria Colegiada-RDC/ANVISA, com fiscalização determinações e intervenções com vistas ao cumprimento das normas. Tais aspectos podem 
ser observados nas UCEs seguintes.

A intervenção seria no sentido de que seja adotado um protocolo onde esse protocolo existe normas que todas obedeçam(...) Existe a RDC e a decisão da ANVISA que estipulam quais são as ações que devem ser observadas pela CCIH e pelos profissionais da saúde(...) Então o órgão se detecta que essas ordens não estão sendo respeitadas que faça cumprir as normas legais aplicando penalidades aos profissionais. com vista a evitar futuras ocorrências de infecção hospitalar, orientar o profissional ao cumprimento da $R D C(. .$.

Neste sentido, com a regulamentação do Sistema Único de Saúde (SUS), na Constituição de $1988^{(6)}$ e na legislação ordinária que se seguiu (Lei 8.080/90 e Lei 8.142/90), a saúde como direito social, passou a ser a mudança fundamental preconizada pelo SUS. O conceito limitado da saúde ou à forma como os serviços estão sendo organizados, exige mudanças, necessitando de uma conceituação ampla sobre a saúde, a criação de novas formas que materializem social e politicamente uma ação cuidadosa integral, como direito de cidadania para os usuários do sistema de saúde no Brasil(14).

Assim, os profissionais falam das diretrizes que envolvem normas a serem cumpridas, ao mesmo tempo em que abordam diferentes implicações para o não controle das infecções hospitalares.

Classe 4 - Implicações legais e práticas dos profissionais do direito na prevenção e controle das infecções hospitalares.

A classe número quatro, associada diretamente com a classe um, constituída pelas 119 UCEs extraídas predominantemente das entrevistas 3 e 14, dos profissionais advogados, odontólogos e médicos na faixa etária de 31 a 40 anos, compreendeu a classe mais significativa.

Os conteúdos semânticos que se encontram agrupados e expostos no Gráfico 1, associados aos elementos de maior destaque nas UCEs, evidenciaram que o profissional de direito tem a função não só de punir, como também, perceber que o profissional de saúde necessita conhecer as implicações legais sobre a IH. Atualmente, esses profissionais estão mais atuantes, participando de cursos para aprimorar seus conhecimentos, a fim de atuarem juridicamente dentro desta área.

Sabe-se que a base para minimizar essa problemática encontra-se na prevenção, capaz de significar uma economia futura para as instituições e menos problema para os profissionais da saúde. Esta idéia pode ser observada nas UCEs exemplificadas a seguir.

Talvez o profissional da área de direito, ele não esteja apenas querendo atuar para punir o profissional e a instituição mas até mesmo mostrar a essas instituições e ao profissional a importância de ter conhecimento das implicações legais sobre a infecção hospitalar(...) Hoje nós temos muitos profissionais da área de direito que também estão atuando na área da saúde ou participando de cursos da área da saúde ou então mesmo atuando apenas como defensor do direito e com isso, não apenas com infecção hospitalar(...) Os pacientes, eles podem recorrer à justiça na questão de se sentirem prejudicados no caso de infecção hospitalar, então os médicos, o serviço, as instituições tem que estar atento e o profissional do direito também tem que conhecer alguns detalhes da infecção hospitalar para poder trabalhar corretamente essa questão(...) No controle das IH, a cada dia cresce a necessidade de novos profissionais do direito que possam atuar dentro desta área(...) Orientar o profissional de saúde como o próprio usuário sobre seus direitos(...) Uma relação onde o direito, o profissional do direito, tem uma responsabilidade muito grande sobre a infecção hospitalar no sentido de que a atuação do advogado, então vai fazer com que cresça na sociedade (...)

Para a efetivação de uma saúde ideal, amparada constitucionalmente, há necessidade de mudanças no âmbito jurídico começando pela reestruturação do próprio Estado, a fim de torná-lo capaz de realizar a saúde como direito universal. Tais exigências são indispensáveis para que o projeto de mudança na saúde aconteça e atenda social e politicamente a população com estratégias sólidas de prevenção e controle das $\mathrm{IH}$, e não represente apenas imposições por meio de pensamentos políticos ou de técnicos arraigados no aparelho do Estado ${ }^{(15)}$.

Dessa forma, pode-se repensar a definição de qualidade na atenção à saúde, definindo a priori como construção de um modelo que tem por finalidade avaliar os serviços, e assim, ser capaz de monitorar e induzir um processo com resultados cada vez mais favorável, entre benefícios e riscos, lembrando que toda instituição pública para atender sua missão, precisa funcionar como um organismo integrado ${ }^{(14)}$.

Foi com esta preocupação que os profissionais, sujeitos desta pesquisa, falaram da necessidade de implementação de medidas de biossegurança capazes de controlar as infecções hospitalares e realizarem práticas profissionais mais seguras, com representações sociais em que os sentimentos constituem a dimensão psicológica importante na lógica de sua estruturação

Classe 2 - Sentimentos dos profissionais acerca do panorama organizacional e funcional na saúde frente às infecções hospitalares.

Esta classe, número dois, encontra-se associada diretamente a classe três, constituída pelas 55 UCEs extraídas predominantemente da entrevista número um do profissional enfermeiro na faixa etária de 41 a 50 anos. Observa-se a presença de elementos sócios-cognitivos e afetivos responsáveis pela objetivação de representações da infecção hospitalar presentes em ancoragens sociais e psicológicos, em que os profissionais se posicionam (dimensão-atitude) frente a infecção hospitalar e a estrutura organizacional e funcional da instituição de saúde, de modo negativo.

Assim, os conteúdos mais freqüentes nas UCEs dessa classe, apresentados no Gráfico 1, compreendem conhecimentos, descrições e explicações sobre as dificuldades que os profissionais têm acerca da estrutura organizacional e funcional da instituição de saúde no que se refere a prevenção e controle das $\mathrm{IH}$.

Os conflitos mencionados pelos sujeitos da pesquisa estão relacionados, por um lado, com a precariedade que se encontram hoje os hospitais públicos, sem condições físicas e sem material para o trabalho adequado dos profissionais da saúde

Neste sentido, é importante observar a aplicação da "teoria de risco", em que são analisadas as condições disponíveis do serviço ao profissional de saúde avaliando o grau de incidência. Nessa teoria, a aritmética correlaciona que quanto maior o risco, menor a responsabilidade do profissional para apurar e quantificar a sanção. No Direito, encontra-se a figura do responsável solidário, ou seja, em que responderá pelo ato não só o seu causador direto, mas também todos os profissionais responsáveis que se envolveram de alguma forma, para causar o dano. As $\mathrm{CClH}$ das instituições têm um papel importantíssimo, para analisar e apurar o causador ou culpado em casos de $\mathrm{IH}^{(16)}$.

Assim, a evidência dessas dificuldades podem ser observadas nas UCEs seguintes:

As dificuldades estão relacionadas às medidas de prevenção, com relação a pessoal a falta de uma educação permanente, com relação à estrutura do hospital, a superlotação(...) Bom, com relação as dificuldades, eu penso assim, de como não há uma educação permanente dos profissionais para e, adotarem medidas, por exemplo, medidas de biossegurança, medidas que vão realmente evitar uma infecção cruzada(...)

A falta de uma política de educação permanente para os profissionais, tem contribuído para dificultar sensivelmente a conquista da realização integral, igualitária e universal dos direitos sociais na saúde, tornando 
inquestionável a necessidade de uma política pública de saúde. Nessa política é importante enfatizar os valores da saúde enquanto direito de cidadania e parte dos direitos universais do ser humano, destacando dentro dos sete eixos dos rumos adicionais desejáveis na construção do SUS, "o desenvolvimento de recursos humanos, de relações de trabalho, de educação permanente, com base nas necessidades e direito da população"(17).

As representações sociais deixam evidentes que as condições oferecidas aos profissionais para a realização dos procedimentos invasivos com a adoção das medidas de biosseguranca, lavagem adequada das mãos e uso de equipamentos de proteção individual (EPI) necessários, constitui grandes dificuldades dos profissional de saúde para que se possa realizar um bom trabalho no ambiente hospitalar prevenindo e controlando a IH. Tais preocupações podem ser observadas nos exemplos seguintes.

\section{(...) Agora um problema seriíssimo que eu vejo, que dificulta essas medidas de prevenção, é a adoção de procedimentos evasivos, quer dizer, totalmente sem condições, quer dizer, pelo fato da demanda ser grande, no caso, por exemplo, de uma endoscopia(...) Os procedimentos invasivos, em que a quantidade material é pequena, insuficiente para atender uma demanda grande da população, então os serviços, são obrigados a atender (...)}

Assim sendo, é observável nos depoimentos dos sujeitos do estudo a repercussão psicossocial da infecção hospitalar, demonstradas por sentimentos negativos de preocupação, tristeza e falta de conscientização, mesclados por sentimentos positivos, como: responsabilidade, alegria, valorização e crença positiva na eficácia de resultados provenientes de ações planejadas e singulares. Tais sentimentos podem ser verificáveis nos exemplos a seguir.

(...) Eu vejo assim, que os profissionais, eles não tem uma preocupação, o hospital não tem preocupação, o governo não tem preocupação com isso, e que a coisa vai cada dia aumentando e, os problemas, acreditam que, se houvesse realmente punições(...) Quando visito os meus pacientes às vezes volto alegre mais as vezes eu volto muito triste porque as condições que o encontro assim, no hospital que eu trabalho, são muito difíceis(...) A crença dos resultados das suas ações, de acreditar que um material está ou não esterilizado, se você pode usar ou não naquela pessoa como no caso de um exame como já falei de uma endoscopia (...)

Nas falas dos profissionais observam-se crenças na esterilização do material a ser utilizado em procedimentos invasivos, assim como na patogenicidade dos microorganismos, como uma manobra para atender ações de prevenção e controle da infecção hospitalar, como algo desvinculado da consciência dos profissionais e, portanto, do contexto de trabalho. Nota-se dificuldade dos profissionais em registrarem situações que evidenciem o estado emocional ou aspectos sociais dos clientes, negligenciando as necessidades de um cuidado holístico, contemplando aspectos biológicos, emocionais, sócio-culturais e espirituais.

Classe 3 - Conhecimentos dos profissionais sobre a prevenção e controle das infecções hospitalares

A classe número três, encontra-se associada diretamente à classe dois, que é constituída por 67 UCEs, conformada com a participação dos sujeitos correspondentes as entrevistas 6 e 10, dos enfermeiros e médicos, na faixa etária de 51 a 60 anos, com conteúdos semânticos apresentados na Figura 1.

Observou-se nas falas dos profissionais de saúde, carência de informações básicas para os mesmos aderirem às medidas de prevenção e controle da $\mathrm{HH}$, apontadas por eles deficitária como: formação e orientação para o controle de IH pelas Instituições formadoras; ações educativas desenvolvidas pela $\mathrm{CCIH}$; observância com o cuidado da pele e lavagem das mãos; considerar os investimentos afetivos envolvidos neste processo e a persistência da prática medicamentosa para solucionar o problema da infecção com antibióticos, aumentando assim, a resistência bacteriana no hospital. Tais colocações podem ser observadas nas UCEs seguintes:

(...) Todos os profissionais eles tem de ser treinados, reciclado e monitorado na questão da infecção hospitalar. E é por isso que o próprio Ministério da Saúde hoje admite que não tenha serviços de saúde, que não tenha Comissão de infecção hospitalar(...) Quando a gente faz o curso de graduação, você tem uma informação bastante resumida de uso de barreiras, de métodos, para controle de infecção, para evitar contaminação (...)

No Brasil, nas últimas décadas, com o surgimento da Aids, existe uma preocupação na literatura sobre a necessidade de maior empenho dos profissionais da área da saúde na mudança de comportamentos e maior compromisso dos mesmos para adoção de práticas seguras e medidas preventivas. Porém essa mudança não tem acontecido, apesar do conhecimento disponível e a maior ênfase dada pelos meios de comunicação a essa problemática.

A formação dos profissionais de saúde, direcionadas a estimular a percepção do risco e a eficácia de medidas de biosegurança ainda constitui um desafio a ser implementado. Enquanto filosofia de trabalho deve ser transmitida por um corpo docente comprometido com estas questões e preparado para ampliar os conteúdos programáticos que atendam os princípios científicos fundamentados na prevenção e controle da $\mathrm{IH}$ nas atividades práticas, devendo atender às necessidades do exercício profissional, em uma estrutura organizacional e funcional que favoreçam a prática de condutas corretas ${ }^{(18)}$

Observa-se nas falas dos profissionais conhecimentos e informações voltadas à preocupação, valorização e importância da adoção de ações de prevenção e controle das $\mathrm{IH}$, como fundamentais para uma prática com eficácia e qualidade, conforme atestam os exemplos a seguirem.

(...) Não se pode lavar a consciência com o uso de antibióticos quando você não lava as mãos corretamente(...) Não se deixe levar por essa maré de trabalho sem se preocupar, sem se lembrar na possibilidade de carrear infecção e procurar trabalhar com anti-sepsia, com prevenção(...) Então muitas coisas eu senti que estava errada e que eu estava realmente correndo risco(...) A gente precisa começar a alertar as pessoas para essas ações, começar a lembrar e acreditar que bactérias são microscópicas, não existe bicho só de barata para cima (...)

Os conteúdos nesta classe identificados, reforçam a necessidade dos profissionais da saúde considerarem dimensões psicossociais frente à infecção hospitalar importantes para o desenvolvimento das ações de prevenção e controle, determinadas pela formação de atitudes, conhecimentos/informações e imagens sobre a infecção hospitalar e a adesão à práticas preventivas e condutas adotadas por esses profissionais.

\section{CONSIDERAÇÕES FINAIS}

No estudo procurou-se, a partir da apreensão das representações sociais das implicações legais da infecção hospitalar construídas por profissionais da saúde e seu controle, salientar aspectos psicossociais envolvidos nas práticas dos profissionais de saúde e direito enquanto determinantes de posicionamentos dos mesmos frente à adoção de medidas preventivas de controle das infecções hospitalares, no contexto hospitalar, com conteúdos conflituosos entre o saber científico e a prática inadequada.

Neste sentido, é o conhecimento cotidiano que permite aos profissionais interiorizar suas práticas profissionais e sociais, experiências e 
comportamentos, utilizando-se de um sistema de interpretação veiculado às formas de comunicação social entre esses profissionais, através da qual é possível aos mesmos construírem e se apropriarem de objetos sociais, ou seja, da adoção de medidas de prevenção ou não.

Os resultados apontam ancoragens sociais, psicológicas e psicossociológias das representações da infecção hospitalar, evidenciando preocupações com conotações positivas e negativas frente às infecções, a partir de comportamentos até certo ponto ambíguos, como: a necessidade de medidas preventivas ea não adoção dessas medidas pelos profissionais; reconhecem os direitos dos usuários embora faz muito pouco para garantir tais direitos.

Dessa forma, as práticas construídas pelos profissionais e usuários são sustentadas por razões sociais, psicológicas, históricas, éticas e culturais, sedimentada pela prática cotidiana instituída e, de forma velada, pelas leis regidas a partir de Portarias, normas e valores institucionais.

As representações sociais sobre as implicações legais da infecção hospitalar são objetivadas por imagens negativas e positivas, dimensionadas em aspectos psicológicos, sociais e culturais vigentes.

Por um lado, essas considerações são refletidas a partir das representações sociais apreendidas e exemplificadas nos conteúdos apresentados nas classes, em que a produção de sentido à infecção hospitalar assentava toda a produção de conhecimentos sobre as implicações legais da infecção hospitalar e seu controle, centrada nas implicações legais da infecção hospitalar e os direitos do usuário.

Por outro lado, os sentidos atribuídos foram sedimentados nos "riscos" que os usuários estão submetidos resultantes de ocorrências causadas por negligência dos profissionais envolvidos no atendimento aos usuários e pela não fiscalização da Agencia Nacional de Vigilância Sanitária (ANVISA) e gestores das instituições de saúde, exigindo que os responsáveis respondam civilmente e penalmente, pelo descaso ou descuido na assistência hospitalar.

Neste estudo os profissionais apontaram dificuldades nas condições de trabalho oferecidas e responsabiliza a estrutura organizacional e funcional do hospital, a superlotação do mesmo, a falta de educação permanente para melhorarem seus conhecimentos centrados na prevenção e controle da infecção hospitalar de maneira que possa resultar na diminuição dos seus índices no ambiente hospitalar.

\section{REFERÊNCIAS}

1. Lacerda, RA. Infecção hospitalar e sua relação com a evolução das práticas de assistência em saúde. In: Lacerda RA. Controle de Infecção em Centro Cirúrgico - Fatos, Mitos e Controvérsia. São Paulo (SP): Atheneu; 2003. p. 9-23.

2. Turrini RNT, Santo Augusto H. Infecção hospitalar e causas múltiplas de morte. J Pediatria 2002;78(6):485-90.

3. Prade SS, Oliveira ST, Rodrigues R, Nunes FA, Félix JK, Pereira M, et al. Estudo Brasileiro da Magnitude das Infecções Hospitalares em Hospitais Terciários. Rev Controle Infecção Hosp 1995;2(2):4-8.

4. Moura MEB. A Infecção Hospitalar no Piauí: a crítica e os aspectos críticos no processo de cuidar em Enfermagem (tese). Rio de Janeiro (RJ): Escola de Enfermagem Anna Nery, Universidade Federal do Rio de Janeiro; 2000.

5. Ministério da Saúde (BR). Portaria 196. Expede na forma de anexos, normas para o controle de IH. Brasília (DF): MS, 1996.

6. Silva AO, Alves MSCF, Moreira MASP, Silva SLF. Utilização da teoria das representações sociais no campo da saúde - UFPB João Pessoa: tendências e perspectivas. In: Coutinho MPL, Lima AS, Oliveira FB, Fortunato ML. Representações Sociais abordagem interdisciplinar. $1^{\mathrm{a}}$ ed. João Pessoa (PB): Universitária UFPB; 2003.

7. Senado Federal (BR). Constituição: República Federativa do Brasil: 1988. Brasília (DF): Centro Gráfico; 1988.

8. Wagner W. Sócio-gênese e características das Representações Sociais. In: Antonia SPM, Denize CO. Estudos Interdisciplinares de Representações Sociais. Goiânia(GO): AB ; 2000.

9. Moscovici S. A Representação Social da Psicanálise. Rio de Janeiro (RJ): Zahar; 1978

10. Jodelet $\mathrm{D}$. Représentations sociales: un domaine en expansion.
In: Jodelet D. Les Représentations sociales. Paris (FRA): PUF; 1997. p. 47-78.

11. Minayo MCS. Pesquisa Social. Teoria, Método e Criatividade, Petrópolis (RJ): Vozes; 1994.

12. Ministério da Saúde (BR). Conselho Nacional de Saúde. Diretrizes e normas regulamentadoras de pesquisa envolvendo seres humanos: Resolução no 196/96. Brasilia (DF): MS; 1996.

13. Reiner MA. Analyse de Donnes Textualles. Paris (FRA): Societé IMAGE; 2000.

14. Costa OV. Direito à saúde no Brasil: entre a prevenção de doenças e o tratamento de doentes. São Paulo Perspec 1999;13(3):137-43.

15. Viana ALA, Fausto MCRL, Luciana D. Política de saúde e eqüidade. São Paulo Perspec 2003;17(1):58-68.

16. Ministério da Saúde (BR). Portaria 2616. Expede na forma de anexos, diretrizes e normas para a prevenção e controle da infecção hospitalar. Brasília (DF): MS; 1998.

17. Puccini PT, Cecílio LCO. A humanização dos serviços e o direito à saúde. Cad Saúde Pública 2004;20(5):1342-53.

18. Elias PE. Estado e saúde. Os desafios do Brasil contemporâneo. São Paulo Perspec 2004;18(3).

19. Antônio LAC. Aspectos legais no Controle de Infecção Hospitalar In: Fernandes AT, Fernandes MOV, Ribeiro Filho, N. Infecção Hospitalar e suas Interfaces na área da Saúde. $1^{\mathrm{a}}$ ed. São Paulo (SP): Atheneu; 2000.

20. Santos NR. Desenvolvimento do SUS, rumos estratégicos e estratégias para visualização dos rumos. Cien Saúde Coletiva 2007;12(2):429-35.

21. Tipple AFV, Pereira MS, Hayashida M, Moriya TM, Sousa ACS O Ensino do Controle de Infecção: um ensaio teórico-prático. Rev Latino-Am Enfermagem 2003;11(2):245-50. 